\title{
EFFECT OF SOIL- STRUCTURE INTERACTION ON HIGH RISE R.C REGULAR FRAME STRUCTURE WITH IRREGULAR BAYS SUBJECTED TO SEISMIC LOAD
}

\author{
M.Pavan Kumar ${ }^{1}$, G.T.Naidu ${ }^{2}$, T.Ashok Kumar ${ }^{3}$ \\ ${ }^{1}$ Asst.Professor, Civil Engineering Department, S.V.P.Engineering College, A.P, India \\ ${ }^{2}$ Assoc.Professor, Civil Engineering Department, S.V.P.Engineering College, A.P, India \\ ${ }^{3}$ M.E.Scholar, Civil Engineering Department, S.V.P.Engineering College, A.P, India
}

\begin{abstract}
Reinforced concrete building structure consist of horizontal member (beam \& slab) and vertical members (columns \& walls), and supported by foundation. The structure is subjected to loads of self-weight, live load, wind load and earthquake load etc. The structural strength of slab and the brick walls is not normally considered in the analysis of the structure Generally the foundation support is assumed as either hinged or fixed support, while foundations transmit the load to the soil medium which undergoes a settlement (vertical) depending on the loads from the structure and characteristics of the soil medium, causing the additional forces in structure. However, this effect is normally neglected in the structural analysis due to its complicated analysis. An attempt is made to analyze the structure considering the foundation soil settlement as define like soil medium by spring. The structure is analyzed for various seismic zones of India. (II, III, IV,\&V), sub grade modulus of soil (Gs) from $12000 \mathrm{kN} / \mathrm{m}^{3}$ to $60,000 \mathrm{kN} / \mathrm{m}^{3}$. The results of the above analysis are used to study the effect of soil - structure interaction on horizontal displacement ' $\delta x$ ' at each floor, and vertical displacement ' $\delta y$ ' at the supports of a building. From the study, it is observed that the maximum percentage of variation in $x$ - trans is 337 percentage with respect to fixed support condition at sub grade modulus of $12,000 \mathrm{kN} / \mathrm{m}^{2} \mathrm{~m}$ at seismic zone V and the maximum percentage of variation in y-trans is 1420 percentage with respect to fixed support at sub grade modulus $12,000 \mathrm{kN} / \mathrm{m}^{2}$ m at seismic zone V. From pilot study, concluded that effect of soil - structure interaction has to consider especially for lower sub grade modulus of soil at higher seismic intensities.
\end{abstract}

KeyWords: Soil structure interaction (SSI), R.C.frame, Seismic load, High rise buildings etc...

\section{INTRODUCTION}

During the last quarter of the 20th century, the importance of dynamic soil-structure interaction for several structures founded on soft soils was well recognized. If not accounted for in analysis, the accuracy in assessing structural safety in the face of earthquakes cannot be accounted for adequately. For this reason, seismic soil-structure interaction analysis has become a major topic in earthquake engineering.

In Earthquake Engineering when the soil medium is relatively soft, the dynamic interaction between the superstructure, its foundation, and the soil medium may become important. During the shaking of an Earthquake, seismic waves are transmitted through the soil from fault rupture to a structure of interest. The wave motion of the soil excites the structure which in turn modifies the input motion by its movement relative to the ground. These interaction phenomena will be called "soil foundation-super structure interaction" or simply "soil structure interaction". Depending upon the material properties of the soil medium, the source of dynamic excitation and the particular type of foundation considered, the response of the structural system can be quite different from the case where the supporting system is rigid. This interaction effect may be especially significant in the frequency band near the resonant frequencies of the super structure because the soft foundation can provide the means for energy absorption. Because of this, the interaction is generally considered to be favorable in earthquake engineering design.

Recent research results in the field of soil-structure interaction indicate that SSI has an important effect on the dynamic response of the structures when the soil is soft. In general, there are three major influences:

1. It will change the dynamic characteristics of the soilstructure system, such as modal frequencies and vibrating shapes. In particular, the fundamental frequency will have significant drops and the rigid body motion of the structure will be produced or enhanced.

2. It will increase the modal damping as some vibrating energy in the structure will be transferred to the soil. This type of damping is called radiation damping.

3. It will influence free-field ground motion (Menglin and Jingning, 1998).In a seismic soil-structure interaction analysis, it is necessary to consider the infinite and layer characteristics of soil strata, and the non-linear behaviors 
of soft soil. The objective of this study is to perform a rigorous seismic non-linear soil-structure interaction analysis in the time domain to satisfy the above requirements while the results are compared with those of fixed based structural analysis. In spite of advantages, however, soil-structure interaction has also contributed additional complications to the analysis:

The influence of non-vertically incident seismic waves: Complicated coupling phenomena may occur for non-vertically incident body wave for surface waves, since those tend to cause rotation as well as translation. This rotation component is automatically neglected while studying translation if the base is assumed to rigid.

The overall dissipation of dynamic energy from the super-structure is quite important for characterizing its response. In the case when interaction is not neglected, the semi-infinite soil medium acts as a sink because the energy is dissipated by geometrical spreading of waves.

The geometrical shape and the rigidity of the super-structure and its foundation can be important. For example, tensional vibration may be induced by horizontal excitation if the superstructure is not symmetrical.

The influence of surrounding buildings may also be significant. The vibration of the nearby foundations can be thought of as additional wave sources. Therefore in densely constructed metropolitan areas, motion of a particular foundation may be amplified or attenuated by the existence of neighboring structures. This effect may be more dominant when the nearby structures are larger and heavier than the one considered.A flexible support may allow larger relative movements between the heavier structural frames, which can cause higher localized stresses

\subsection{Objective of present study:}

The objective of this study is to analyze the three dimensional high rise building under seismic load of a structure. This structure is analyzed for different values of sub grade modulus and for different seismic zones. The sub grade modulus is assigned to all the footings in a structure. The results of analysis ( $\delta \mathrm{x}$ at each floor and $\delta$ yat the supports) for various values of sub grade modulus at different seismic loads are considered to study.

\subsection{Scope:}

For the purpose of Comparison, building type, floor system, floor area, bay size and column height are kept constant throughout the study.

Ordinary moment resisting frames (OMRF) with response reduction factor of 3.0 and importance factor 1 (general building) is considered throughout the study. The study is made for 30 storey structure with plan dimensions of $20 \mathrm{~m}$ X $20 \mathrm{~m}$, in all the seismic zones of India (Zones II to Zone $\mathrm{V})$

\section{REVIEW OF LITERATURE}

CHANDRASEKARAN et al: The foundation differential settlements influence the load transmitted from one column to another, and hence the redistribution of forces in the superstructure members. The magnitude of the load redistribution is dependent on the stiffness of the elements of the superstructure as well as the magnitude of the differential settlement (Wood and Larnach, 1975). MIYAHARAet al said that the Foundation settlements may introduce new conditions of load distribution in the structure that cause distress and cracking of its elements, and may even lead to stress reversal. Soil settlement on the other hand, is a function of the flexural rigidity of the superstructure. The structural stiffness can have a significant influence on the distribution of the column loads and moments transmitted to the foundation of the structure, and load redistribution may modify the pattern of or mitigate settlements. Increased stiffness of the frame generally reduces differential settlement and when the soil is soft the interaction is beneficial (Goschy $\left.{ }^{15}, 1978\right)$.

\subsection{Modulus of subgrade reaction:}

For analysis of beams and slabs resting on a soil medium, engineers have been using a classical mathematical model called the Winkler's model, where the behavior of the soil is simplified by means of fictitious springs placed continuously underneath the structure. The corresponding springs constant " $\mathrm{K}$ " is called "the modulus of the sub grade reaction of soil". So far based on this concept, many computer codes have been developed by engineers for the analysis of the beams and slabs on an elastic foundation; the user of the code has to determine the value of " $\mathrm{K}$ " to represent the soil. There is no easy way to determine the value of " $\mathrm{K}$ " because its value is not unique for a given type of soil (as suggested in some text books of foundation engineering). Usually the soil is stratified, having different thickness, and the value of an equivalent " $\mathrm{K}$ " has to be at least a function of the thickness of the soil layer, even when its material properties remain same. The larger the thickness, the lower is the " $\mathrm{K}$ " value. If the analysis is performed for a uniformly distributed load on a slab, there is no provision for differential settlement or bending moments or for shear forces in the structures in disregard of reality. Many researchers have proved this lack of uniqueness of " $\mathrm{K}$ " in the past.

BOWLES have suggested that the value of " $K$ " has to be augmented on the edges of the slabs and have emphasized the need for more research on this topic. In other words, the value of " $K$ " varies in the domain of the slab for different material and geometric properties of the soil. To circumvent this condition, a two-parameter model has been suggested by Pasternak (1954) and later by Vlasov and Leontev (1966). But to get consistent results, one has to perform some iterative procedure (Vallabhan and Daloglu 1997, 1999; Vallabhan and Das 1988, 1989; Straughan 1990; Turhan 1992).

These procedures are still not very popular among practical engineers.

\subsection{Coefficient of subgrade reaction:}

The coefficient of sub grade reaction (modulus of foundation, sub grade modulus) is defined as the ratio 
between the pressure against the foundation or mat and settlement at a given point

\section{$\mathbf{k}=\mathbf{q} / \mathbf{s}$}

Where $\mathrm{k}=$ coefficient of sub grade reaction, point,

$q=$ pressure against the foundation or mat at a given

$\mathrm{s}=$ settlement of the same point of foundation or mat

In other words, the coefficient of sub grade reaction is the unit pressure required to produce a unit settlement. In clay soils, settlements under the load takes place over a long period and the settlement should be determined based on the final settlement. On purely granular soils, settlement takes place shortly after load application

Above equation is based on two simplifying assumptions:

1. The value $\mathrm{k}$ is independent of the magnitude of pressure.

2 . The value of $k$ has the same value for every point on the surface of foundation of mat.

\section{GEOMETRIC MODELING OF STRUCTURE}

A three-dimensional multi storied structure is considered for soil structure interaction. Fig. 3.1 shows the plan, considered for the analysis. The plinth area of the building is $20 \mathrm{~m} \times 20 \mathrm{~m}$, the total height of the building is $92 \mathrm{~m}$, and the height of each storey is taken as $3 \mathrm{~m}$. The slab is $0.15 \mathrm{~m}$ thick and the column dimensions are $0.75 \mathrm{~m} \mathrm{x}$ $0.30 \mathrm{~m}$.

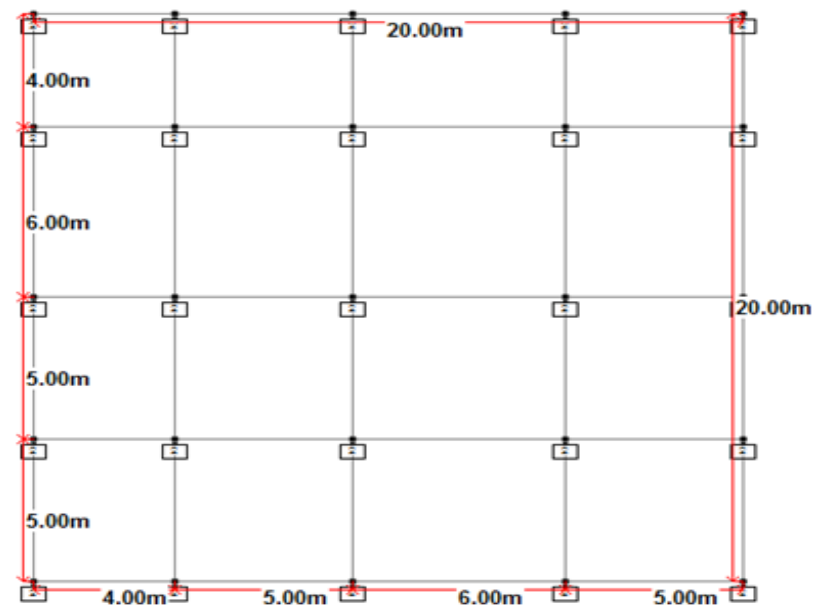

Fig. 3.1 Plan of Thirty Storied Building

\section{Details of a Building:-}

1.

lan area of the building $\quad 20 \mathrm{~m} \times 20 \mathrm{~m}$

Thickness of the slab $\quad 0.15 \mathrm{~m}$

Height of each floor $\quad 3 . \mathrm{m}$

2.

ize of the columns

3. Size of the beams

4. Type of soil

5. Intensity of live load

$$
0.75 \mathrm{~m} \times 0.3 \mathrm{~m}
$$$$
0.45 \mathrm{~m} \times 0.3 \mathrm{~m}
$$

Medium stiff clay

$2 \mathrm{kN} / \mathrm{m}^{2}$

6. Sub grade modulus (Gs) $12,000 \mathrm{kN} / \mathrm{m}^{3}$ to $60,000 \mathrm{kN} / \mathrm{m}^{2}$

The structural part of this problem is a
Multiple-bay high rise reinforced concrete structure subjected to gravity plus lateral loading. The details of the frame are shown in Fig. 3.1. For the analysis the column base is connected to Footing as a Plate mat assuming a constant area of $1.0 \mathrm{~m}^{2}$, and $0.15 \mathrm{~m}$ thick. This structure is analyzed for different values of sub grade modulus ranging from $12,000 \mathrm{kN} / \mathrm{m}^{3}$ to $60,000 \mathrm{kN} / \mathrm{m}^{3}$. The sub grade modulus is calculated by relationGs $=40 * \mathrm{~F}^{*} \mathrm{q}_{\mathrm{a}}$ whereq $\mathrm{q}_{\mathrm{a}}$ is bearing capacity of the soil. This sub grade modulus is assigned to all the footings in a structure. From the loads obtained from this analysis the area of the footing is calculated by the relation Area $=$ Force $/ q_{a}$ (where $q_{a}$ is bearing capacity of the soil). The results of analysis ( $\delta x$ at each floor and $\delta y$ at the supports) for various values of sub grade modulus in different seismiczones are considered to study the effect of soil structure interaction.

\subsection{Calculation of loads:}

i. Dead Load: Dead load per unit area of the floor which includes floor slab, beam, half the weight of columns above and below the floor, partition walls, etc. thickness of the member multiplied by density of the material used by the member gives the dead load in $\mathrm{kN} / \mathrm{m}^{2}$.

ii. Live Load: Live load is taken as $2 \mathrm{kN} / \mathrm{m}^{2}$

iii. Seismic Load: ( IS 1893-2002)

$\mathrm{Z}=$ zone factor: $0.1,0.16,0.24$, and 0.36 .

$\mathbf{V}_{\mathrm{b}}=\mathbf{A}_{\mathbf{h}} \mathbf{w}$

Here $\mathrm{V}_{\mathrm{b}}=$ Base shear

$\mathrm{A}_{\mathrm{h}}=$ Seismic coefficient

$\mathrm{W}=$ Seismic weight of building

$\mathrm{Ah}=\mathrm{ZI} / 2 \mathrm{R}(\mathrm{Sa} / \mathrm{g})$

$\mathrm{I}=$ Impact factor

$\mathrm{I}=1.0$ for residential building

$\mathrm{I}=1.5$ for public building

$\mathrm{IS}=456-2000, \mathrm{OMRF} 3$

Where, OMRF - ordinary moment resisting frame

$\left(\mathrm{S}_{\mathrm{a}} / \mathrm{g}\right)$ - Spectrum acceleration coefficient

\subsection{Modeling of foundation soil:}

\section{a. Sub grade Modulus (Gs):}

The various sub grade modulus values considered for the analysis are given by Josef E Bowles.

\section{b. Safe Bearing Capacity of Soil Medium (q):}

Soil bearing earth pressure theory assumes that upon exceeding a certain stress condition, rupture surfaces are formed in the soil mass. Thus, the stress causing the formation of these rupture surfaces may be considered as the ultimate bearing capacity of the soil. The safe bearing capacity of the soil is determined according to the following formula. $\mathrm{Gs}=40 * \mathrm{q}_{\mathrm{a}} *(\mathrm{~S} . \mathrm{F}) \mathrm{kN} / \mathrm{m}^{3}$

\subsection{Parameters:}

The effect of Soil-Structure Interaction under Dynamic response of a multistoried building is analyzed for possible alternate configurations by varying different parameters. 
1. Height of the Building $(\mathrm{H})$ :

Heights of a Building are considered for the

soil structure interaction.

$\mathrm{H}$ is the total height of a structure.

$\mathrm{H}=92 \mathrm{~m}$

2. Sub grade Modulus of Soil (Gs ):

The structure is defined to rest on the soil having different values of sub grade modulus 12000, 24000, 36000, 48000, $60000 \mathrm{kN} / \mathrm{m}^{3}$ given by Joseph E Bowles in Foundation Structure located in Different Seismic zones for analysis:

\section{RESULTS \& DISCUSSIONS}

The middle frame of the building is considered as it is critical compared to the other frames in XY plane. The effect of soil structure interaction is studied by the horizontal and vertical deflections $(\delta x \& \delta y)$ of the extreme column nodes of middle frame of the building. The results and analysis of the structure (horizontal \& vertical deflections i.e., $\delta x \& \delta y)$ are obtained.

A parametric study is conducted on the effect of soil structure interaction under a seismic zone of a structure by considering various parameters such as 30 storey structure, building Gs assumed to be situated in different Seismic zones (Z-II, Z-III, Z-IV \& Z-V), variation of soil properties i.e., from loose sand to medium dense sand ( $\mathrm{Gs}=\mathrm{sub}$ grade modulus of foundation soil).

The superstructure load (dead load \& live load) are taken as vertical loads due to self-weight of the building and lateral loads due to seismic zones. The parametric study conducted in the present work is mainly based on various values of foundation soil sub grade modulus ranges from $12,000 \mathrm{kN} / \mathrm{m}^{3}$ to $60,000 \mathrm{kN} / \mathrm{m}^{3}$. The 30 storey building and the seismic zones are Z-II,Z-III,Z-IV\&Z-V are considered according to IS 1893-2002.(part-I)

\subsection{0-storey Building at Seismic Zone- II (X-} trans):

From Graphs (i.e, fig $4.1 \& 4.2$ ) the following results were observed

1. The percentage of increased displacement in ' $x$ ' direction for sub-grade modulus of $\quad 12000 \mathrm{kN} / \mathrm{m}^{3}$ with respect to fixed support is $269 \%$.

2. The percentage of increased displacement in ' $x$ ' direction for sub-grade modulus of $24000 \mathrm{kN} / \mathrm{m}^{3}$ with respect to fixed support is $255 \%$.

3 . The percentage of increased displacement in ' $x$ ' direction for sub-grade modulus of $36000 \mathrm{kN} / \mathrm{m}^{3}$ with respect to fixed support is $252 \%$.

4. The percentage of increased displacement in ' $x$ ' direction for sub-grade modulus of $48000 \mathrm{kN} / \mathrm{m}^{3}$ with respect to fixed support is $251 \%$.

5 . The percentage of increased displacement in ' $x$ ' direction for sub-grade modulus of $60000 \mathrm{kN} / \mathrm{m}^{3}$ with respect to fixed support is $250 \%$.

And also observed that the percentage of displacement in ' $x$ ' direction increases from $250 \%$ to $263 \%$ with decreasing of sub-grade modulus from $60000 \mathrm{kN} / \mathrm{m}^{3}$ to $12000 \mathrm{kN} / \mathrm{m}^{3}$.

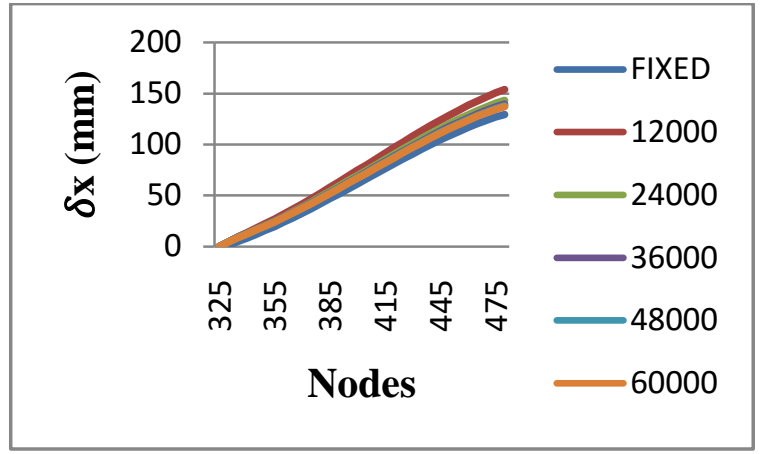

Fig - 4.1 30 Storey building at seismic zone II (X-trans)

\begin{tabular}{|l|l|l|l|l|l|}
\hline $\begin{array}{l}\text { Subgrade } \\
\text { modulus }\end{array}$ & 12000 & 24000 & 36000 & 48000 & 60000 \\
\hline $\begin{array}{l}\text { Max \% } \\
\text { Variation }\end{array}$ & 269 & 255 & 252 & 251 & 250 \\
\hline $\begin{array}{l}\text { Min \% } \\
\text { Variation }\end{array}$ & 19 & 11 & 8 & 7 & 6 \\
\hline
\end{tabular}

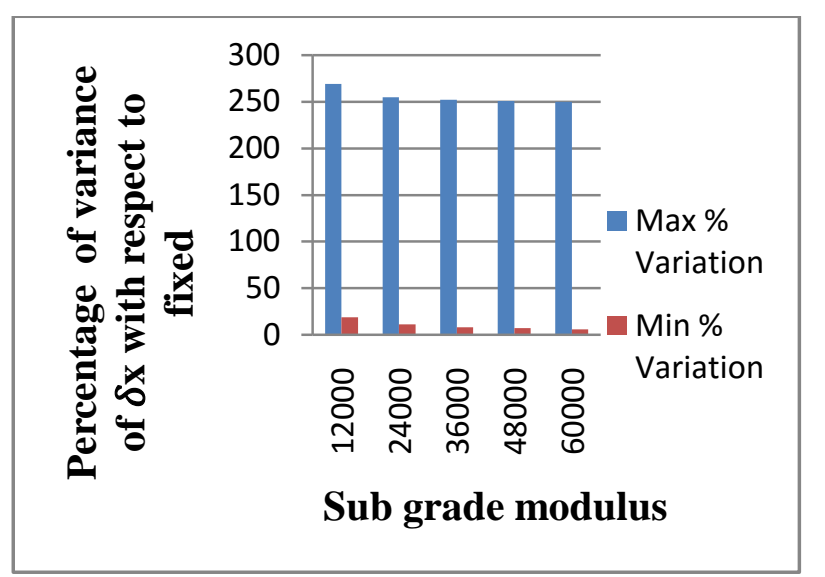

Fig - 4.2 Percentage of variance of $\delta x$ with respect to different sub grade modulus at seismic zone II (X-trans)

\subsection{0- Storey Building at Seismic Zone- II (Y- trans):}

From Graphs (i.e, fig $4.3 \& 4.4$ ) the following results were observed

1. The percentage of increased displacement in ' $y$ ' direction for sub-grade modulus of $12000 \mathrm{kN} / \mathrm{m}^{3}$ with respect to fixed support is $1420 \%$.

2. The percentage of increased displacement in ' $y$ ' direction for sub-grade modulus of $24000 \mathrm{kN} / \mathrm{m}^{3}$ with respect to fixed support is $725 \%$.

3. The percentage of increased displacement in ' $y$ ' direction for sub-grade modulus of $36000 \mathrm{kN} / \mathrm{m}^{3}$ with respect to fixed support is $487 \%$.

4. The percentage of increased displacement in ' $y$ ' direction for sub-grade modulus of $48000 \mathrm{kN} / \mathrm{m}^{3}$ with respect to fixed support is $367 \%$.

5 . The percentage of increased displacement in ' $y$ ' direction for sub-grade modulus of $60000 \mathrm{kN} / \mathrm{m}^{3}$ with respect to fixed support is $294 \%$.

And also observed that the percentage of displacement in ' $y$ ' direction increases from $294 \%$ - $1420 \%$ with decrease of 
sub-grade modulus from $60000 \mathrm{kN} / \mathrm{m}^{3}$ to $12000 \mathrm{kN} / \mathrm{m}^{3}$.

While comparing percentage of increase in $\mathrm{x}$-displacement with $\mathrm{y}$ - displacement, observed that the percentage of increased $\mathrm{x}^{-}$displacement variation is lower than $\mathrm{y}$ displacement in Zone II for the 30 - storey building.

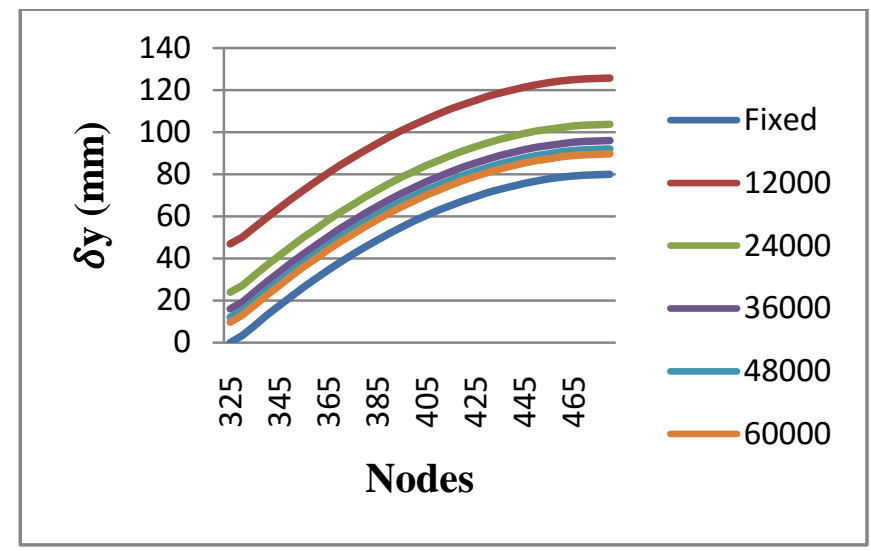

Fig - 4.3 30 Storey building at seismic zone II (Y-trans)

\begin{tabular}{|l|l|l|l|l|l|}
\hline $\begin{array}{l}\text { Subgrade } \\
\text { modulus }\end{array}$ & 12000 & 24000 & 36000 & 48000 & 60000 \\
\hline $\begin{array}{l}\text { Max \% } \\
\text { Variation }\end{array}$ & 1420 & 725 & 487 & 367 & 294 \\
\hline $\begin{array}{l}\text { Min \% } \\
\text { Variation }\end{array}$ & 58 & 30 & 21 & 16 & 13 \\
\hline
\end{tabular}

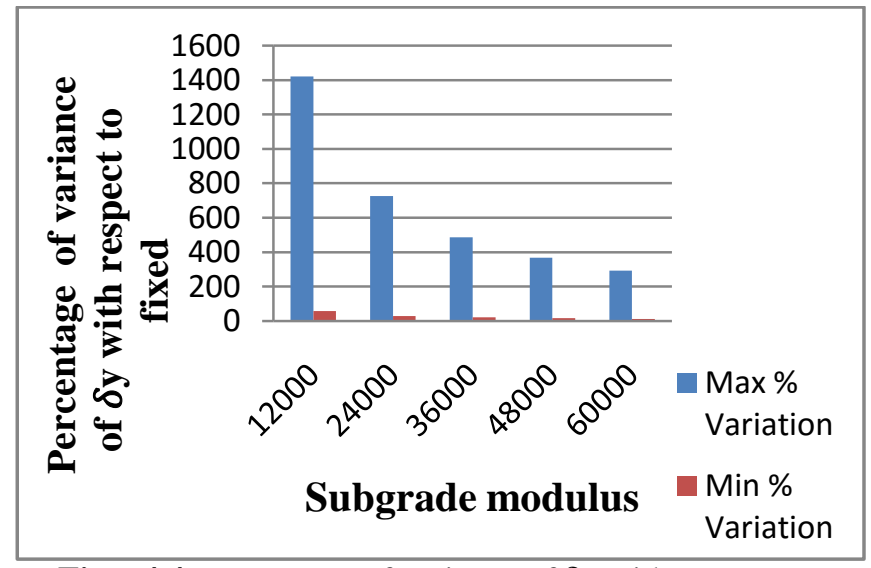

Fig - 4.4 Percentage of variance of $\delta y$ with respect to different sub grade modulus at seismic zone II (Y-trans)

\subsection{0-Storey Building at Seismic Zone- III (X- trans):}

From Graphs (i.e, fig $4.5 \& 4.6$ ) the following results were observed

1. The percentage of increased displacement in ' $x$ ' direction for sub-grade modulus of $12000 \mathrm{kN} / \mathrm{m}^{3}$ with respect to fixed support is $303 \%$.

2. The percentage of increased displacement in ' $x$ ' direction for sub-grade modulus of $24000 \mathrm{kN} / \mathrm{m}^{3}$ with respect to fixed support is $280 \%$.

3. The percentage of increased displacement in ' $x$ ' direction for sub-grade modulus of $36000 \mathrm{kN} / \mathrm{m}^{3}$ with respect to fixed support is $271 \%$.
4. The percentage of increased displacement in ' $x$ ' direction for sub-grade modulus of $48000 \mathrm{kN} / \mathrm{m}^{3}$ with respect to fixed support is $268 \%$.

5 . The percentage of increased displacement in ' $x$ ' direction for sub-grade modulus of $60000 \mathrm{kN} / \mathrm{m}^{3}$ with respect to fixed support is $265 \%$.

And also observed that the percentage of displacement in ' $x$ ' direction increases from $265 \%$ to $303 \%$ with decrease of sub-grade modulus from $60000 \mathrm{kN} / \mathrm{m}^{3}$ to $12000 \mathrm{kN} / \mathrm{m}^{3}$.

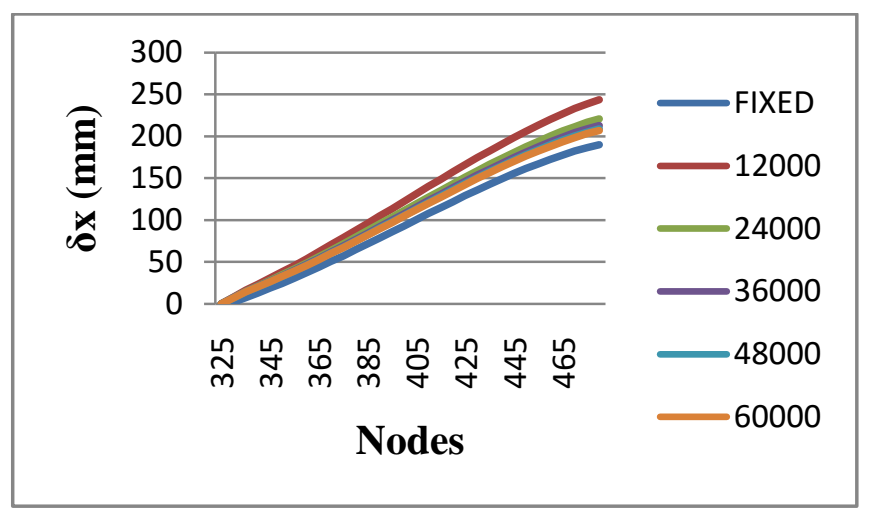

Fig - 4.5 30 Storey building at seismic zone III X-trans

\begin{tabular}{|l|l|l|l|l|l|}
\hline $\begin{array}{l}\text { Subgrade } \\
\text { modulus }\end{array}$ & 12000 & 24000 & 36000 & 48000 & 60000 \\
\hline $\begin{array}{l}\text { Max \% } \\
\text { Variation }\end{array}$ & 303 & 280 & 271 & 268 & 265 \\
\hline $\begin{array}{l}\text { Min \% } \\
\text { Variation }\end{array}$ & 28 & 16 & 12 & 10 & 9 \\
\hline
\end{tabular}

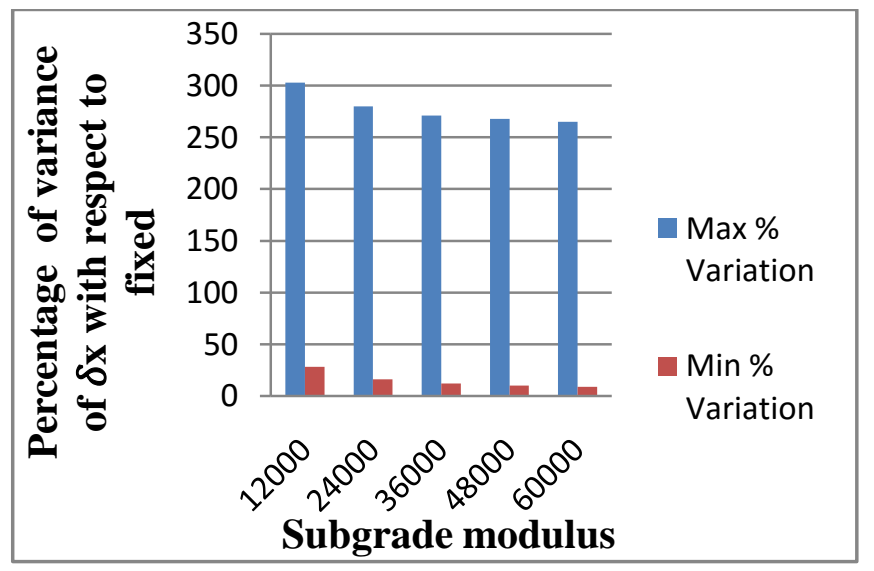

Fig - 4.6 Percentage of variance of $\delta x$ with respect to different sub grade modulus at seismic zone III (X-trans)

\subsection{0-Storey Building at Seismic Zone- III (Y- trans):}

From Graphs (i.e, fig $4.7 \& 4.8$ ) the following results were observed

1. The percentage of increased displacement in ' $y$ ' direction for sub-grade modulus of $12000 \mathrm{kN} / \mathrm{m}^{3}$ with respect to fixed support is $1420 \%$.

2. The percentage of increased displacement in ' $y$ ' direction for sub-grade modulus of $24000 \mathrm{kN} / \mathrm{m}^{3}$ with respect to fixed support is $725 \%$. 
3. The percentage of increased displacement in ' $y$ ' direction for sub-grade modulus of $36000 \mathrm{kN} / \mathrm{m}^{3}$ with respect to fixed support is $487 \%$.

4. The percentage of increased displacement in ' $y$ ' direction for sub-grade modulus of $48000 \mathrm{kN} / \mathrm{m}^{3}$ with respect to fixed support is 367 percentage

5 . The percentage of increased displacement in ' $y$ ' direction for sub-grade modulus of $60000 \mathrm{kN} / \mathrm{m}^{3}$ with respect to fixed support is $294 \%$.

6. And also observed that the percentage of displacement in ' $y$ ' direction increase from $294 \%$ to $1420 \%$ with decrease of sub-grade modulus from $60000 \mathrm{kN} / \mathrm{m}^{3}$ to $12000 \mathrm{kN} / \mathrm{m}^{3}$

While comparing percentage of increase in $\mathrm{x}$-displacement with $y$ - displacement, observed that the percentage of increased $\mathrm{x}$ - displacement variation is lower than the $\mathrm{y}$ displacement in Zone III for the 30 - storey building.

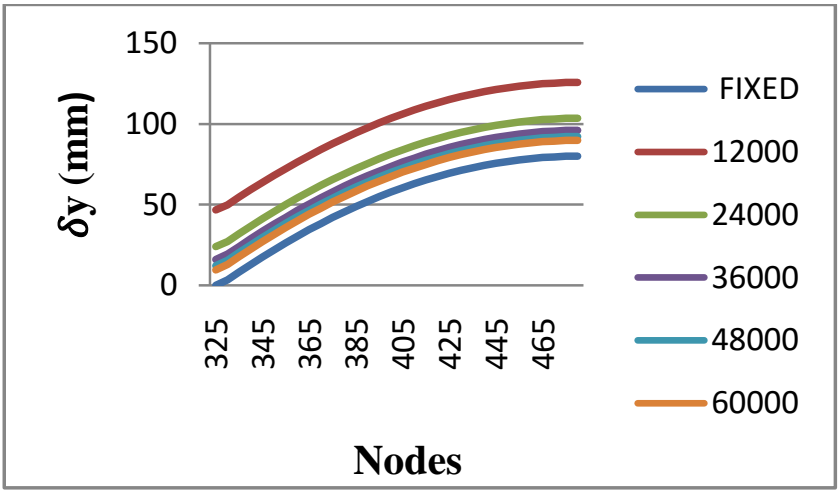

Fig - 4.7 30 Storey building at seismic zone III Y- trans

\begin{tabular}{|l|l|l|l|l|l|}
\hline $\begin{array}{l}\text { Subgrade } \\
\text { modulus }\end{array}$ & 12000 & 24000 & 36000 & 48000 & 60000 \\
\hline $\begin{array}{l}\text { Max \% } \\
\text { Variation }\end{array}$ & 1420 & 725 & 487 & 367 & 294 \\
\hline $\begin{array}{l}\text { Min \% } \\
\text { Variation }\end{array}$ & 58 & 30 & 21 & 16 & 13 \\
\hline
\end{tabular}

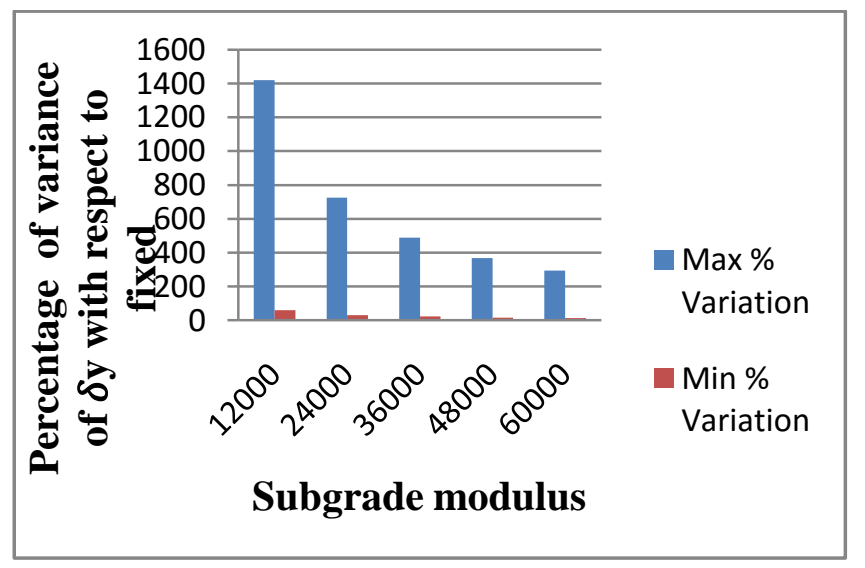

Fig - 4.8 Percentage of variance of $\delta y$ with respect to different sub grade modulus at seismic zone III ( $\mathrm{Y}$ - trans)

\subsection{0-Storey Building at Seismic Zone- IV (X-} trans):

From Graphs (i.e, fig $4.9 \& 4.10$ ) the following results were observed

1. The percentage of increased displacement in ' $x$ ' direction for sub-grade modulus of $12000 \mathrm{kN} / \mathrm{m}^{3}$ with respect to fixed support is $323 \%$.

2 . The percentage of increased displacement in ' $\mathrm{x}$ ' direction for sub-grade modulus of $24000 \mathrm{kN} / \mathrm{m}^{3}$ with respect to fixed support is $293 \%$.

3. The percentage of increased displacement in ' $x$ ' direction for sub-grade modulus of $36000 \mathrm{kN} / \mathrm{m}^{3}$ with respect to fixed support is $283 \%$.

4. The percentage of increased displacement in ' $x$ ' direction for sub-grade modulus of $48000 \mathrm{kN} / \mathrm{m}^{3}$ with respect to fixed support is $277 \%$.

5 . The percentage of increased displacement in ' $x$ ' direction for sub-grade modulus of $60000 \mathrm{kN} / \mathrm{m}^{3}$ with respect to fixed support is $273 \%$.

And also observed that the percentage of displacement in ' $x$ ' direction increases from $273 \%$ to $323 \%$ with decrease of sub-grade modulus from $60000 \mathrm{kN} / \mathrm{m}^{3}$ to $12000 \mathrm{kN} / \mathrm{m}^{3}$.

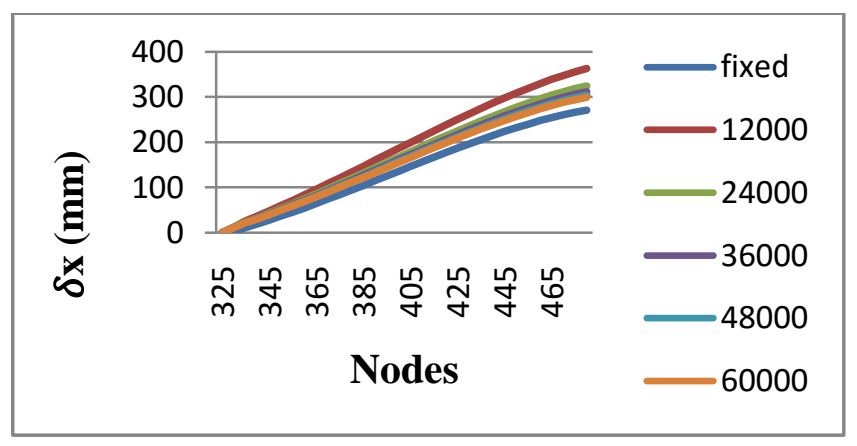

Fig - 4.9 30 Storey building at seismic zone IV X-trans

\begin{tabular}{|l|l|l|l|l|l|}
\hline $\begin{array}{l}\text { Subgrade } \\
\text { modulus }\end{array}$ & 12000 & 24000 & 36000 & 48000 & 60000 \\
\hline $\begin{array}{l}\text { Max \% } \\
\text { Variation }\end{array}$ & 323 & 293 & 283 & 277 & 273 \\
\hline $\begin{array}{l}\text { Min \% } \\
\text { Variation }\end{array}$ & 33 & 20 & 15 & 13 & 11 \\
\hline
\end{tabular}

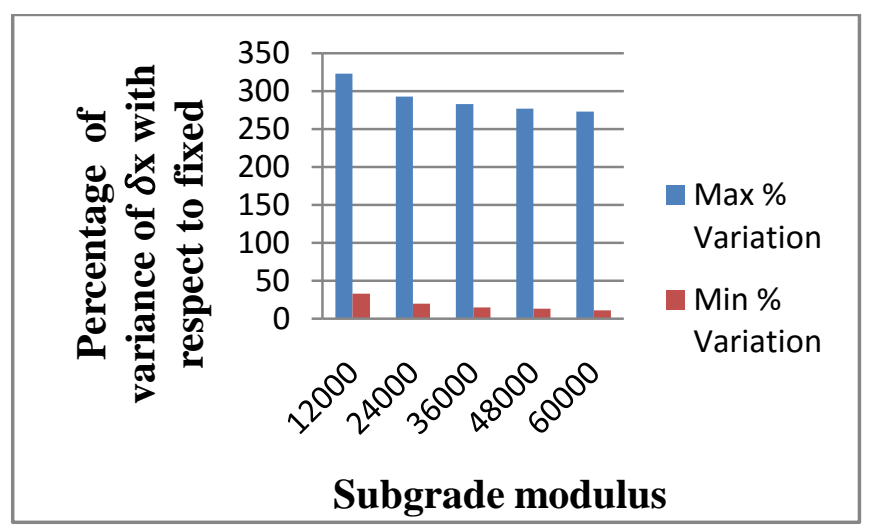

Fig - 4.10 Percentage of variance of $\delta$ x with respect to different sub grade modulus at seismic zone IV (X-trans)

4.6 30-Storey Building at Seismic Zone- IV (Ytrans):

From Graphs (i.e, fig $4.11 \& 4.12$ ) the following results 
were observed

1. The percentage of increased displacement in ' $y$ ' direction for sub-grade modulus of $12000 \mathrm{kN} / \mathrm{m}^{3}$ with respect to fixed support is $1420 \%$.

2. The percentage of increased displacement in ' $y$ ' direction for sub-grade modulus of $24000 \mathrm{kN} / \mathrm{m}^{3}$ with respect to fixed support is $725 \%$.

3. The percentage of increased displacement in ' $y$ ' direction for sub-grade modulus of $36000 \mathrm{kN} / \mathrm{m}^{3}$ with respect to fixed support is $487 \%$.

4. The percentage of increased displacement in ' $y$ ' direction for sub-grade modulus of $48000 \mathrm{kN} / \mathrm{m}^{3}$ with respect to fixed support is $367 \%$.

5 . The percentage of increased displacement in ' $y$ ' direction for sub-grade modulus of $60000 \mathrm{kN} / \mathrm{m}^{3}$ with respect to fixed support is $294 \%$.

And also observed that the percentage of displacement in ' $y$ ' direction increases from $294 \%$ to $1420 \%$ with decrease of sub-grade modulus from $60000 \mathrm{kN} / \mathrm{m}^{3}$ to $12000 \mathrm{kN} / \mathrm{m}^{3}$.

While comparing percentage of increase in $\mathrm{x}$-displacement with $y$ - displacement, observed that the percentage of increased $x^{-}$displacement variation is lower the $y$ displacement in Zone IV for the 30 - storey building.

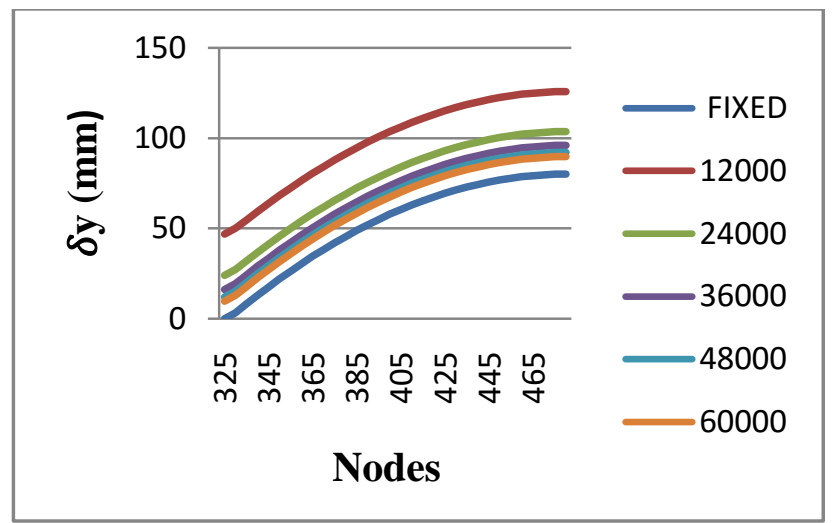

Fig - 4.11 30 Storey building at seismic zone IV Y- trans

\begin{tabular}{|l|l|l|l|l|l|}
\hline $\begin{array}{l}\text { Subgrade } \\
\text { modulus }\end{array}$ & 12000 & 24000 & 36000 & 48000 & 60000 \\
\hline $\begin{array}{l}\text { Max \% } \\
\text { Variation }\end{array}$ & 1420 & 725 & 487 & 367 & 294 \\
\hline $\begin{array}{l}\text { Min \% } \\
\text { Variation }\end{array}$ & 58 & 30 & 21 & 16 & 13 \\
\hline
\end{tabular}

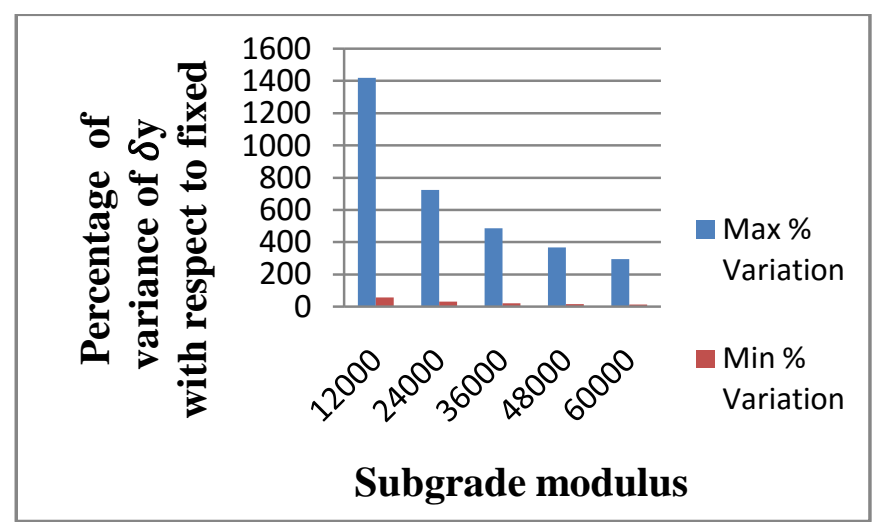

Fig - 4.12 Percentage of variance of $\delta y$ with respect to different sub grade modulus at seismic zone IV (Y-trans)

\subsection{0- Storey Building at Seismic Zone- V (X-} trans):

From Graphs (i.e, fig $4.13 \& 4.14$ ) the following results were observed

1. The percentage of increased displacement in ' $x$ ' direction for sub-grade modulus of $12000 \mathrm{kN} / \mathrm{m}^{3}$ with respect to fixed support is $337 \%$.

2. The percentage of increased displacement in ' $x$ ' direction for sub-grade modulus of $24000 \mathrm{kN} / \mathrm{m}^{3}$ with respect to fixed support is $303 \%$.

3. The percentage of increased displacement in ' $x$ ' direction for sub-grade modulus of $36000 \mathrm{kN} / \mathrm{m}^{3}$ with respect to fixed support is $290 \%$.

4. The percentage of increased displacement in ' $\mathrm{x}$ ' direction for sub-grade modulus of $48000 \mathrm{kN} / \mathrm{m}^{3}$ with respect to fixed support is $284 \%$.

5 . The percentage of increased displacement in ' $x$ ' direction for sub-grade modulus of $60000 \mathrm{kN} / \mathrm{m}^{3}$ with respect to fixed support is $279 \%$.

And also observed that the percentage of displacement in ' $x$ ' direction increases from $279 \%$ to $337 \%$ with decrease of sub-grade modulus from $60000 \mathrm{kN} / \mathrm{m}^{3}$ to $12000 \mathrm{kN} / \mathrm{m}^{3}$.

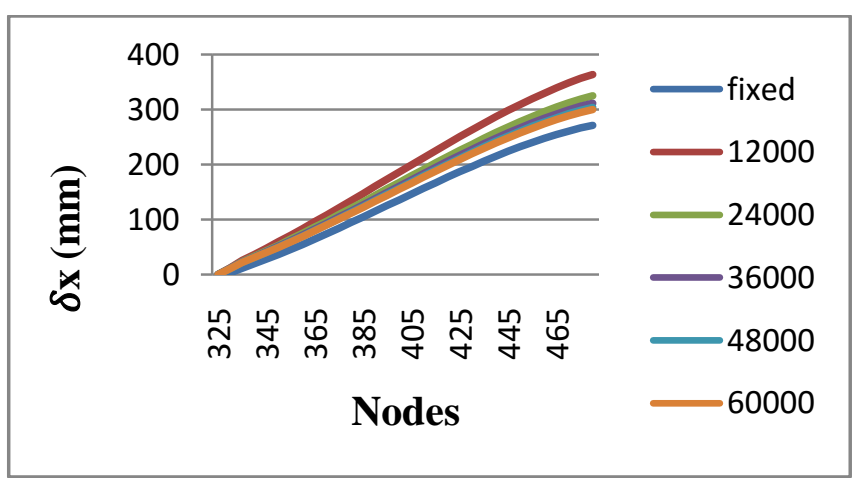

Fig - 4.13 30 Storey building at seismic zone V X-trans

\begin{tabular}{|l|l|l|l|l|l|}
\hline $\begin{array}{l}\text { Sub grade } \\
\text { modulus }\end{array}$ & 12000 & 24000 & 36000 & 48000 & 60000 \\
\hline $\begin{array}{l}\text { Max \% } \\
\text { Variation }\end{array}$ & 337 & 303 & 290 & 284 & 279 \\
\hline $\begin{array}{l}\text { Min \% } \\
\text { Variation }\end{array}$ & 37 & 22 & 17 & 14 & 12 \\
\hline
\end{tabular}

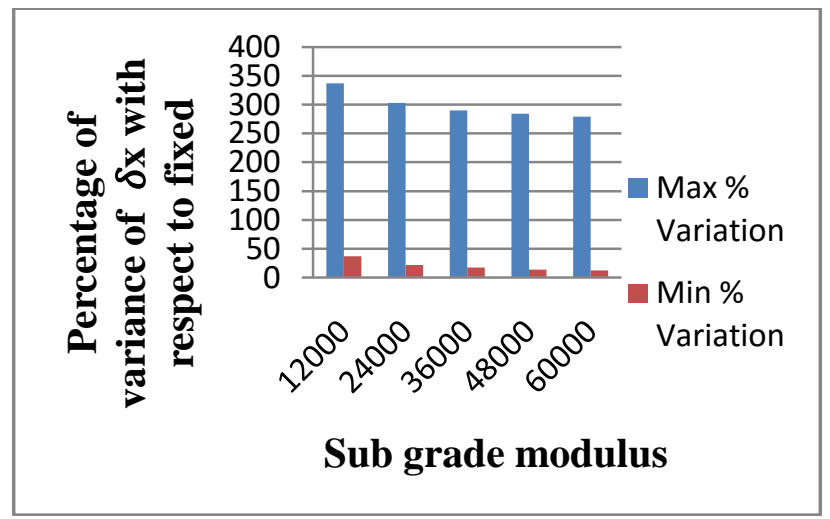

Fig - 4.14 Percentage of variance of $\delta x$ with respect to different sub grade modulus at seismic zone V (X-trans) 


\subsection{0-Storey Building at Seismic Zone-V (Y-trans)}

From Graphs (i.e, fig $4.15 \& 4.16$ ) the following results were observed

1. The percentage of increased displacement in ' $y$ ' direction for sub-grade modulus of $12000 \mathrm{kN} / \mathrm{m}^{3}$ with respect to fixed support is $1420 \%$.

2. The percentage of increased displacement in ' $y$ ' direction for sub-grade modulus of $24000 \mathrm{kN} / \mathrm{m}^{3}$ with respect to fixed support is $725 \%$.

3 . The percentage of increased displacement in ' $y$ ' direction for sub-grade modulus of $36000 \mathrm{kN} / \mathrm{m}^{3}$ with respect to fixed support is $487 \%$.

4. The percentage of increased displacement in ' $y$ ' direction for sub-grade modulus of $48000 \mathrm{kN} / \mathrm{m}^{3}$ with respect to fixed support is $367 \%$.

5 . The percentage of increased displacement in ' $y$ ' direction for sub-grade modulus $60000 \mathrm{kN} / \mathrm{m}^{3}$ with respect to fixed support is $294 \%$.

And also observed that the percentage of displacement in ' $y$ ' direction increases from $294 \%$ to $1420 \%$ with decrease of sub-grade modulus from $60000 \mathrm{kN} / \mathrm{m}^{3}$ to $12000 \mathrm{kN} / \mathrm{m}^{3}$

While comparing percentage of increase in $\mathrm{x}$-displacement with $y$ - displacement, observed that the percentage of increased $x-$ displacement variation is lower the $y$ displacement in Zone $\mathrm{V}$ for the 30 - storey building.

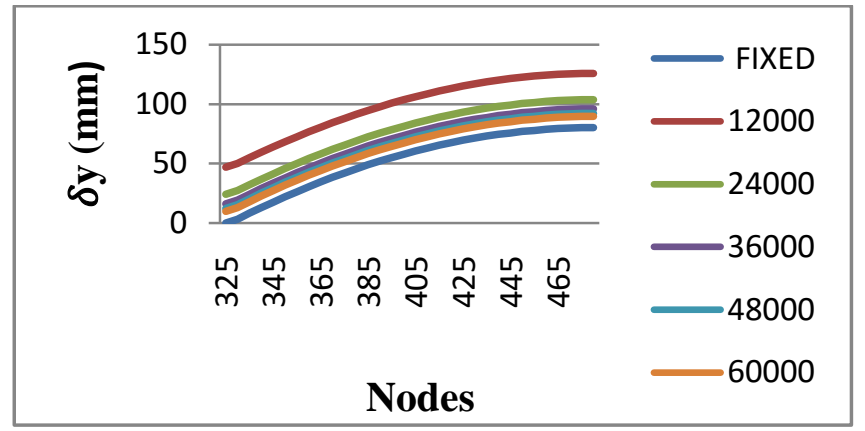

Fig - 4.15 30 Storey building at seismic zone V Y-trans

\begin{tabular}{|l|l|l|l|l|l|}
\hline $\begin{array}{l}\text { Sub grade } \\
\text { modulus }\end{array}$ & 12000 & 24000 & 36000 & 48000 & 60000 \\
\hline $\begin{array}{l}\text { Max } \\
\text { Variation }\end{array}$ & 1420 & 725 & 487 & 367 & 294 \\
\hline $\begin{array}{l}\text { Min } \\
\text { Variation }\end{array}$ & 58 & 30 & 21 & 16 & 13 \\
\hline
\end{tabular}

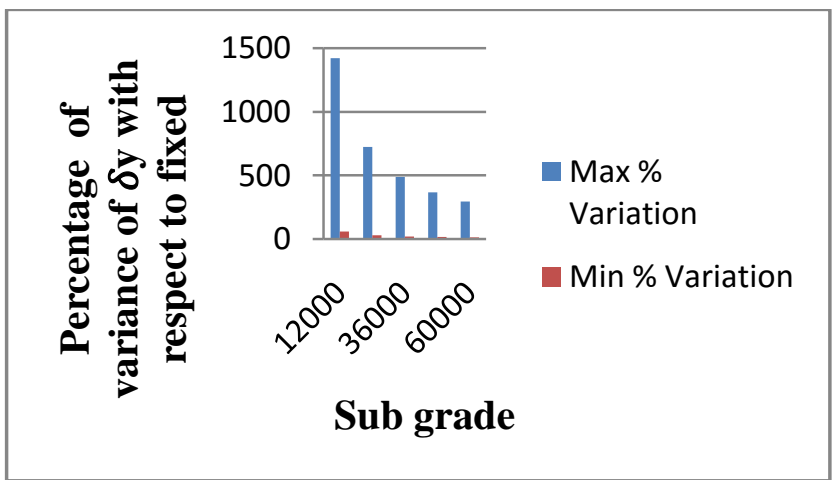

Fig - 4.16 Percentage of variance of $\delta y$ with respect to different sub grade modulus at seismic zone V (Y-trans)

\section{CONCLUSIONS:}

The structure is analyzed by considering soil-structure interaction subjected to seismic load by using STAAD Pro2007. It is acted upon by vertical loads due to self-weight of the structure and lateral loads due to seismic load. It is analyzed for different parameters such as soil sub grade modulus ranging from $12,000 \mathrm{kN} / \mathrm{m}^{3}$ to $60,000 \mathrm{kN} / \mathrm{m}^{3}, 30$ storey building and structure located at different seismic zones. i.e Z-II,Z-III,Z-IV\& Z-V. The variation of horizontal displacement $(\delta \mathrm{x})$ and the vertical displacement $(\delta \mathrm{y})$ are studied and following conclusions were drawn.

(1)From the study, observed that the percentage of displacement in $\mathrm{x} \& \mathrm{y}$ direction are increased with decreasing sub grade modulus at all seismic zones.

(2)While comparing percentage of increase in $\mathrm{x}$ displacement with $y$ - displacement, observed that the percentage of increased $\mathrm{x}$ - displacement variation is lower than $\mathrm{y}$ - displacement in Zone II for the 30 - storey building.

(3)The maximum percentage of variation in $\mathrm{x}$ - trans is 337 percentage with respect to fixed support at sub grade modulus $12,000 \mathrm{kN} / \mathrm{m}^{2} / \mathrm{m}$ at seismic zone $\mathrm{V}$.

(4)The minimum percentage of variation in $\mathrm{x}$ - trans is 250 percentage with respect to fixed support at sub grade modulus $60,000 \mathrm{kN} / \mathrm{m}^{2} / \mathrm{m}$ at seismic zone II

(5)The maximum percentage of variation in $y$ - trans is 1420 percentage with respect to fixed support at sub grade modulus $12,000 \mathrm{kN} / \mathrm{m}^{2} / \mathrm{m}$ at seismic zone $\mathrm{V}$.

(6)The minimum percentage of variation in $\mathrm{x}$ - trans is 294 percentage with respect to fixed support at sub grade modulus $60,000 \mathrm{kN} / \mathrm{m}^{2} / \mathrm{m}$ at seismic zone II.

(7)From the study, concluded that effect of soil - structure interaction has to consider especially for lower sub grade modulus of soil at higher seismic intensities.

\section{REFERENCES:}

[1] Bowles, J.E., 1988. Foundation Analysis and Design, $4^{\text {th }}$ Edition. McGraw-H II, San Franciso, California

[2] Celib q i ,M. and Okawa, I. (1998). Proc. UJNR Workshop on Soil-Structure Interaction, USGS.

[3] Chamecki, S. (1956). "Structural Rigidity in Calculating Settlement", Journal of Soil Mechanics and Foundation Division, ASCE, Vol.82, SM 1, pp.119.

[4] Desari (1982)," Finite Element Process For 3Dimensional soil structure".

[5] IS 875 Part-3 Indian Standard Code of Practice for "Design of Wind Loads".

[6] IS456-2000 Indian Standard Code of Practice for "Plain and Reinforced Concrete".

[7] King, G.J.W. and Chandrasekaran , V.S(1947).”An Assessment of the Effects of Interaction Between a Structure and its Foundation", Proceedings, Conference on Settlement of Structures,Cambridge,Penteck Press, London,pp.368-383.

[8] Lee, I.K. and Brown, P.T. (1972). "StructureFoundation Interaction Analysis", Journal of Structure.Division, ASCE, Vol.96No.ST11,pp.24132431. 
[9] Lee, I.K and Harrison, H.B.(1970). "Structure and Foundation Interaction Theroy", Journal of Structure Division, ASCE,Vol.96 No.ST2,pp.177-197.

[10] 10. Meyerhof, G.G (1953). "Some Recent Foundation Research and its Application to Design" The Structural Engineer,Vol.31,pp.151-167.

[11]G.V.RAMA RAO \& M.PAVAN KUMAR (2012). "Effect of soil structure interaction under wind load at different wind zones using STADD PRO 2007'IJEAR International Journal Of Education and Applied Research Volume 4 ISSUE SPL-2

[12] Meyerhof,G.G. (1947)." The Settlement Analysis of Building Frames" , The Structural Engineer,Vol.25,pp.369-409.

[13] Miyahara,F. and Ergatoudis. J.G (1976). "Matrix Analysis of Structure Foundation", Journal of Structure division ,ASCE, Vol.102, No.ST1,pp.261265

[14] Sedar Soyoz, K OnderCetin,HalukSucuoglu (2007) “ Effects of Soil Structural Interaction and Base Isolation on Seismic Performance of Foudation Soil" , $4^{\text {th }}$ International Conference on Earthquake Geotechnical Engineering ICGGE, pp No :1183

[15] Siddharth g.shah, Solanki CH. Desari J.A(2010) "Soil Structure Iteraction Analysis Method",International Journal Of Civil and Structural Engineering Vol 2. NO:1,2011, ISSN 0976-4399

[16] Stewart, J.P.Fenves,G.L and Seed, R.B (1999),.““ Sesmic Soil Structure Interaction in Building” Journal of Geo-Technical and Geo-Environmental engineering Vol.125.

[17] Strat Pro-2007 Technical Reference "Reasearch Engineers In International".

[18] Wod,L.A and Larnach,W.J.(1975)."The Interactive Behaviour of a Soil-Structure System and its Effect on Settlements" Proceedings of the Technical Session of a Symposium held at University of New South Wales,Australia, pp.75-88.

[19] Goschy, B. (1978). "Soil-Foundation-Structure Interaction". Journal of the Structure Division, ASCE, Vol.104, No. ST5 pp.749-761.

[20] R.J.Scavuzzo (1974) "A Review of Soil Structure Interaction Effects in the Sesmic Analysis", Journal of the Structural Division, ASCE 97 EM5. 